\title{
Os bastidores da comunicação de risco: a UMinho em tempos de pandemia
}

\author{
https://doi.org/10.21814/uminho.ed.24.6
}

\author{
José Gabriel Andrade
}

José Gabriel Andrade (ORCID: 0000-0002-9778-5865) é doutorado em Ciências da Comunicação, Professor Auxiliar do Instituto de Ciências Sociais da Universidade do Minho e investigador do Centro de Estudos de Comunicação e Sociedade (CECS). Leciona e investiga na área da Comunicação Organizacional e Estratégica e das Novas Tecnologias de Informação e da Comunicação.

\section{Teresa Ruão}

Teresa Ruão (ORCID: 0000-0002-9723-8044 ) é doutorada em Ciências da Comunicação, Professora Associada do Instituto de Ciências Sociais da Universidade do Minho e investigadora do Centro de Estudos de Comunicação e Sociedade (CECS). Foi Vice-Presidente do Instituto de Ciências Sociais da Universidade do Minho, de 2010 a 2019 e é atualmente Diretora-Adjunta do CECS. Leciona e investiga na área da Comunicação Organizacional e Estratégica.

\section{Madalena Oliveira}

Madalena Oliveira (ORCID: 0000-0001-8866-0000) é doutorada em Ciências da Comunicação, Professora Auxiliar do Instituto de Ciências Sociais da Universidade do Minho e investigadora do Centro de Estudos de Comunicação e Sociedade (CECS). Ensina nas áreas de Semiótica, Linguagens e Jornalismo e os seus interesses de investigação inscrevem-se nos estudos de rádio e de som, políticas de comunicação e jornalismo. 


\section{INTRODUÇÃO: CRISE(S) E SOCIEDADE DE RISCO}

A história das civilizações, como a história das organizações, é frequentemente narrada por referência a momentos críticos, como as guerras ou os períodos de recessão económica. Para além dos grandes empreendimentos que geram progresso e desenvolvimento, os períodos de rutura são, de facto, marcos especialmente relevantes da crónica das sociedades. Representam a mudança, a passagem, a transformação e a renovação. Se, num primeiro momento, se confundem com a ideia de calamidade ou tragédia, a posteriori significam essencialmente pontos de viragem, com um antes e um depois. E embora estejam inevitavelmente associados à ideia de impasse, perigo, tensão ou conflito, estes episódios são, em rigor, fenómenos de transição.

A etimologia situa a palavra crise no campo da medicina. Com origem grega, a krisis era um termo usado pelos médicos para referir o momento decisivo de uma doença. A partir do momento crítico, o doente evoluiria para a cura ou para a morte (Holton, 1987, p. 504). O primeiro sentido do étimo remete, portanto, para uma espécie de turn, que ainda hoje explicará por que razão as mudanças de paradigma - na ciência como na arte - estão de algum modo ligadas à experiência da crise. A própria evolução das épocas por que identificamos a História é o resultado da vivência de processos que, emergindo de modo mais ou menos brusco, por vezes inesperado, impõem uma transformação.

Tenha a natureza que tiver, por definição, a crise não é, em princípio, um estado permanente. Podendo variar em termos de duração, ela é sempre cíclica, um processo temporário, tem um caráter de exceção no curso regular das coisas. A crise é, por outro lado, metamórfica, porque dela nunca se regressa a um ponto anterior imperturbado. Remetendo ao desassossego, à instabilidade e à incerteza, a crise é, no entanto, sempre consequente.

Pelo que implica de interrupção de uma certa harmonia, a crise "decide" o futuro, mas é ao mesmo tempo um apelo à resolução e à distinção, em tudo o que estas ações correspondem a separar e a julgar. Por isso, tanto no Latim como no Grego, o substantivo crise está, num segundo sentido, igualmente ligado à critica (Thomä, Festl \& Grosser, 2015, p. 14). Todos os momentos de crise são, então, momentos propícios 
ao desenvolvimento do pensamento crítico. Supóem ação ponderada, reflexão, análise e definição de estratégia.

Vulgarizado pelos média, que o utilizam como sinónimo frequente de conflito ou revolução, por exemplo, o conceito de crise é hoje central nas Ciências Sociais e Humanas (Koselleck \& Richter, 2006, p. 399). A partir do século XVIII, evoluiu do sentido clínico para a expressão metafórica dos momentos decisivos da história, da política, da economia, da religião ou mesmo das artes. Talvez nenhuma outra época como a nossa tenha incorporado tanto o termo crise no discurso público, do senso comum à narrativa científica. Num tempo que se vive em aceleração, como sugeria Paul Virilio (2000), a experiência da crise mundializou-se, não só porque as crises têm hoje feições globais, mas também porque se estendem a todas as manifestaçôes da própria vida.

A palavra crise já não serve só a ciência económica nem exprime apenas o contexto negativo e depressivo de cadeias de produção, comercialização e consumo. Hoje, fala-se também de crise ambiental, crise política, crise de valores, crise de identidade, crise de cidadania e crise sanitária. Todos os setores da vida social e coletiva e todas as instituições - públicas ou privadas - são permeáveis à experiência da crise. Na saúde, no trabalho, nas relaçôes, na fé, na política, o termo crise tornou-se recorrente. Da crise dos combustíveis à crise dos refugiados, a todo o instante uma qualquer crise tem valor-notícia, porquanto o jornalismo e os média se interessam por tudo o que rompe com a normalidade e tem caráter extraordinário. O tempo que vivemos é, a todos os títulos, um tempo de crise e um tempo em crise, um tempo consciente da crise e exposto à notícia da crise e dos seus efeitos.

Seja no âmbito individual (a crise da adolescência ou a crise da meia idade), seja no âmbito institucional (a crise da família ou a crise da educação), o momento crítico é, por definição, um momento de precariedade. Nele se exprime uma condição frágil, um estado vulnerável ao contingente, uma inaptidão para o funcionamento ordinário. E nele se jogam todas as faces da insegurança: o incerto, o inconstante, o imprevisível, o inesperado e o irregular. Referindo-se à crise da cultura, Moisés de Lemos Martins reconhece que "na contemporaneidade, a nossa situação é de desconforto e mal-estar", porque deixámos de ter garantidos "um fundamento sólido, um território conhecido e uma identidade segura” (Martins, 2017, p. 177-178). 
$\mathrm{Na}$ radicalização da crise está também a perceção de que a sociedade moderna é uma sociedade de risco, uma expressão cunhada pelo sociólogo alemão Ulrich Beck no livro Risk society: towards a new modernity (2000), publicado originalmente em alemão (Risikogesellschaft), em 1986. Atribuindo a origem do perigo e da insegurança ao desenvolvimento científico e industrial e à modernização, Beck refere-se ao risco como uma espécie de crise iminente, de crise sempre prestes a acontecer. Para Moisés de Lemos Martins, "as vertigens da crise e do fim andam associadas ao risco", que, por sua vez, "veio acrescentar uma dimensão nova à nossa experiência". Tal como a crise, que se declina em todos os matizes, também o risco se generaliza "em todos os setores da experiência - risco tecnológico, ecológico, capital de risco, risco nos investimentos, risco no casamento, no relacionamento íntimo, comportamento de risco" (Martins, 2017, p. 85).

O risco já não é, portanto, redutível às ameaças dos desastres, ou crises naturais. O risco é social. Ao contrário da crise, que é, por aceção, episódica, eventualmente frequente, mas incidental, o risco é uma condição permanente. Está-se sempre em risco: em risco de perder o emprego, em risco de ficar doente, em risco de contágio, em risco de falência, em risco de incêndio, em risco de extinção, em risco de vida. Como em nenhum outro tempo, a consciência do risco orienta a ação humana para uma preocupação com o futuro e para um sentido de prevenção. Os fluxos de informação - eles próprios muitas vezes em risco de manipulação - estão hoje vergados ao imperativo da antecipação, da instrução e da orientação para o cálculo dos perigos. A associação que se estabelece entre sociedade da informação e sociedade do conhecimento não tem outro propósito senão o de atribuir à gestão da comunicação a responsabilidade de promover a consciência do risco.

Os média têm hoje, com efeito, um papel decisivo na comunicação do risco. Garantindo o direito à informação e combatendo o risco de desinformação, as instituiçóes mediáticas tornam visível a ameaça tanto da guerra como da catástrofe. Num texto em que se refere aos "riscos da comunicação na comunicação dos riscos”, Paulo Serra explica que "são o agendamento e a tematização dos riscos pelos média que conferem a esses mesmos riscos visibilidade” (Serra, 2006, p. 6). Mas a comunicação de risco não é um exclusivo dos média nem depende unicamente de processos de mediatização. Ela é também uma competência que hoje se espera de todas as organizaçóes. Expoente 
máximo da experiência do risco e da crise, a pandemia provocada pela propagação da COVID-19 pôs em evidência o caráter decisivo dos processos de comunicação interna e externa das instituiçóes, ao mesmo tempo que pôs à prova a eficácia de planos de comunicação orientados para a ação. Nos bastidores da comunicação de crise, analisamos a prestação da UMinho em tempos de pandemia.

\section{AS CRISES E A COMUNICAÇÃO DE RISCO}

As organizações enfrentam cenários de crise mais frequentemente do que imaginam ou admitem. Trata-se de acontecimentos mais ou menos imprevisíveis, que ocorrem em momentos inesperados e tendem a ameaçar a sobrevivência da organização e o bem-estar dos seus públicos. As crises podem ter naturezas diversas, de origem financeira, tecnológica ou ambiental, mas o que as distingue de outros eventos organizacionais é o facto de integrarem sempre o risco de consequências negativas para a segurança organizacional, comunitária ou pública. Ainda que muitos lhe apontem também o benefício de criar oportunidades (Coombs \& Holladay, 2010; Hurst, 1995; Meyers \& Holusha, 1986; Ulmer et al., 2007; Witt \& Morgan, 2002).

De facto, e segundo Coombs (1999), uma crise constitui uma ameaça maior para uma organização e para os seus stakeholders, mas pode ser superada, constituindo sempre, como sugeriram Fink (1986) ou Regester (1989), um ponto de viragem na vida organizacional, para o melhor ou para o pior. Ou seja, a crise é uma situação disruptiva, que resulta de um acontecimento ameaçador, com consequências para a performance e para a reputação organizacional, mas só é verdadeiramente prejudicial se a ameaça não for controlada. Além disso, as crises podem ser eventos isolados ou fazer parte de um padrão de desempenho organizacional (que caracteriza alguns setores com incidentes críticos frequentes, como a aviação ou a indústria petrolífera) e que podem ainda afetar todo o tipo de organizaçóes, lucrativas e não-lucrativas.

Desta argumentação resulta o entendimento de que as crises podem ser geridas. Aliás, a Gestão de Crises constituiu um tema de investigação com amplo desenvolvimento nos últimos anos, mas que se havia afirmado já na década de 1980, com o estudo de casos como a crise do Tylenol da Johnson \& Johnson (Benson, 1988; Fink, 1986). 
É convicção dos investigadores do campo que uma crise bem gerida pode proteger a organização e os seus stakeholders, evitando os piores cenários (Coombs \& Holladay, 2010). Para tal foram desenvolvidos vários modelos de trabalho (Fink, 1986; Smith, 1990), todos replicando o entendimento de que a Gestão de Crises acontece em três fases: pré-crise, crise e pós-crise. A fase da pré-crise envolve os esforços para evitar o aparecimento do problema e preparar a organização para lidar com as suas consequências, caso a prevenção não resulte. A fase da crise é a etapa da resposta a um acontecimento real e compreende a ativação de protocolos de emergência e de comunicação. A fase pós-crise corresponde ao desenvolvimento de práticas que sistematizam esforços de aprendizagem e a entrada em momentos de mudança (Coombs, 2007). Gerir as crises é, portanto, um processo organizacional que acontece em várias etapas, integrando medidas preventivas, planos de atuação e avaliações pós-crise.

Contudo, a Gestão de Crise não implica apenas modelos de reação a situações críticas; pressupóe também que estas podem ser evitadas, através de ações de gestão do risco. $\mathrm{Na}$ verdade, uma crise parece ser um risco tornado real. Como sustenta Heath (2010, p. 3), “à medida que o risco se manifesta (como aconteceu quando o Furacão Katrina atingiu Nova Orleães e outras partes da Costa do Golfo), a crise acontece”. Assim, grande parte do trabalho de Gestão de Crises destina-se a identificar riscos e a evitar que estes se transformem em crises, ou seja, que ganhem a força e configuração de situações que podem afetar negativamente uma organização ou o espaço público (Williams \& Olaniran, 1998). E a comunicação do risco constitui uma parte valiosa do processo de prevenção e preparação das crises.

A Comunicação de Risco é, assim, constituída de atividades de produção e troca de mensagens entre as partes interessadas acerca da natureza, significado e controlo de uma situação de risco (Reynolds \& Seeger, 2005). Na sua essência, a Comunicação de Risco é, primeiramente, um processo interativo de troca de informações e opinióes entre os membros da organização para identificar, avaliar e gerir riscos potenciais (através da formação de um gabinete de crise), para depois se transformar num diálogo entre as organizações que criam os riscos e os stakeholders que podem vir a ser atingidos pelo risco. Ou seja, a Comunicação de Risco é parte integrante do necessário exercício contínuo de análise de risco das organizações e supõe "um processo de comunicação 
transacional entre indivíduos e organizaçôes, em relação ao tipo, causa, grau, significância, incerteza, controle e, sobretudo, perceção geral do risco" (Palenchar, 2005, p. 752).

Apesar da sua natureza preventiva, a Comunicação de Risco também pode ser necessária na fase de resposta às crises. Prestar informaçốes e ajustar expetativas parece ajudar os públicos afetados pela crise a protegerem-se física e psicologicamente (Sturges, 1994). Quando pedimos aos membros de uma comunidade para ajustarem as suas atitudes e adotarem certos comportamentos, estes serão mais recetivos às mensagens se souberem o que isso significa e se acreditarem que a mudança comportamental, de facto, ajudará (Coombs, 2010). Neste sentido, a Comunicação de Risco deve auxiliar no processo de explicação dos problemas às comunidades e deve criar uma maior sensibilidade junto dos públicos para reagirem ao risco e evitarem a crise. Aliás, o desenvolvimento da sensibilidade dos stakeholders ao risco é um aspeto crítico para evitar a crise ou reagir a esta. Assim, se numa primeira fase a Comunicação de Risco se traduz em avaliações internas sobre probabilidades e severidades, numa segunda etapa implica desenhar planos de comunicação adequados à população-alvo, mensagens relevantes para as audiências e a integração de tudo numa estratégia coerente.

Refira-se ainda, pelo caso em estudo, que a Comunicação de Risco tem sido amplamente trabalhada no campo da Comunicação em Saúde, com o propósito de desenvolver conhecimentos e modelos estratégicos de atuação para prevenir o público sobre os riscos associados a determinados comportamentos (Reynolds \& Seeger, 2005). E, neste contexto, várias investigaçôes mostram que as consequências de uma pandemia dependem, em grande medida, de um plano da Comunicação de Risco em saúde. A comunicação deve instruir, informar, motivar para a proteção, construir confiança nas autoridades e evitar rumores. A comunicação da pandemia maximiza a capacidade do público para agir como parceiro efetivo, promove a contenção, reduz resistências e ajuda na recuperação (Dyer, 2009; Vaughan \& Tinker, 2009). Por estas razôes, quando a saúde pública está em perigo, as autoridades são aconselhadas a desenvolver planos de emergência que incluam programas de Comunicação de Risco para diminuir o impacto da ameaça (OMS, 2010) ${ }^{1}$.

1 https://www.who.int/risk-communication/background/en/ (consultado a 26/06/2020). 
A Comunicação de Risco entronca assim com as práticas e pensamento sobre a Comunicação de Crise. A Comunicação de Crise entra em ação quando os riscos não são controlados e inclui os esforços de comunicação estratégica das organizaçôes, para prevenir ou reparar perceções durante uma situação de crise ou de desastre (Benoit, 1997; Coombs, 2014; Reynolds \& Seeger, 2005; Salgado et al, 2010; Seeger, 2006). A Comunicação de Crise pode ser definida como a recolha, processamento e disseminação de informações necessárias para lidar com uma situação de emergência.

Segundo Coombs (2009), podemos distinguir dois tipos de Comunicação de Crise: aquela que se destina à gestão do conhecimento e a que visa a gestão das reaçôes dos stakeholders. A interação destinada à gestão do conhecimento envolve a recolha e análise de informaçôes sobre a situação de emergência, bem como a partilha de conhecimentos e tomadas de decisões (interna e externamente). É o que acontece nos bastidores da crise e envolve o trabalho da equipa de gestão de crise com o objetivo de criar respostas públicas à situação de emergência. A gestão da reação dos stakebolders compreende os esforços comunicativos para influenciar o modo como os públicos percebem a crise, a organização e a resposta à situação. Esta última é a área de Comunicação de Crises mais explorada, sob a forte influência da Comunicação Estratégica, já que o envolvimento dos públicos pode melhorar ou piorar a crise (Coombs, 2014). Em alguns casos, esta comunicação, que Sturges (1994) chamou de "ajustamento", pode assumir a forma de campanhas nos média tradicionais ou nas redes sociais, incluindo mensagens com informações, expressões de simpatia, conselhos ou ações corretivas, classificadas como "boas práticas" (Burgoon et al., 1995; Littlefield et al. 2010).

\section{NOSSOS PÚBLICOS, NOVOS PÚBLICOS}

$\mathrm{Na}$ investigação, os públicos de Comunicação Estratégica têm sido orientados por um núcleo de questóes centrais que Botan e Soto (1998) identificam como: (a) definição, o que são os públicos; (b) segmentação, como diferenciar significativamente os públicos; (c) função, quais os papéis que diferentes públicos desempenham na sociedade; (d) processo, como é que os públicos ganham existência e respondem de determinada forma. Estas questôes têm sido abordadas por autores de diferentes perspetivas com evidente hegemonia da perspetiva situacional introduzida por Grunig 
e Repper (1992). Segundo este ponto de vista, considera-se que um público resulta de um estado motivado por uma situação problemática e não constitui um estado de consciência permanente. Acredita-se que os públicos aparecem como respostas a situações problemáticas e que se auto-organizam para as resolver. Esta perspetiva considera a segmentação dos públicos através de determinadas variáveis. As variáveis apontadas por Grunig e Repper (1992) são as inferidas (cognições, atitudes e perceções) e as objetivas (demográficos, padrôes de uso dos média, localização geográfica). A construção deste modelo está associada à maioria dos estudos na área do Marketing, da Publicidade e das Relações Públicas.

A teoria situacional de públicos de Grunig e Repper (1992) inscreve-se num contexto mais abrangente, procurando defender um modelo de gestão para a Comunicação Estratégica. A preocupação principal foi a de construir um quadro de referência que explicasse a evolução do comportamento de determinados grupos sociais face a uma determinada organização. Foram definidos três estados do desenvolvimento desses grupos: o estado de stakeholder, o estado de público e o estado dos assuntos. Os stakeholders são entendidos como aqueles que afetam uma organização com as suas decisóes ou são afetados pelas decisóes da organização. Quando os stakeholders reconhecem um problema, aumentam o seu nível de participação e, se se dispóem ao envolvimento para fazer face a esse problema, passam para um estado de públicos, podendo aí permanecer durante mais ou menos tempo. Por último, caso os públicos não fiquem satisfeitos com o comportamento de determinada organização, pode chegar-se ao estado dos assuntos ou das polémicas (Eiró-Gomes \& Duarte, 2005). As variáveis situacionais que estão envolvidas na passagem dos stakebolders a públicos incluem: (a) o reconhecimento do problema, que leva à procura de informação; (b) o reconhecimento de constrangimentos, que desencoraja a comunicação uma vez que as pessoas não comunicam sobre assuntos em relação aos quais sentem que não podem fazer nada e (c) o nível de envolvimento, como a perceção cognitiva de um indivíduo acerca da sua conexão com uma dada situação. É mais provável que um público seja ativo quando as pessoas que o constituem percebem que aquilo que uma organização faz os envolve (Nível de Envolvimento), que as consequências do que uma organização faz constituem um problema (Reconhecimento do Problema) e que não vão ficar constrangidas 
se fizerem algo acerca do problema (Reconhecimento de Constrangimentos) (Eiró-Gomes \& Duarte, 2005).

Com o avanço das tecnologias de informação e de comunicação e, observando a transformação dos públicos, faz sentido reportar para a Comunicação Estratégia a proposta de Sonia Livingstone (2005), que apresenta a noção de audiências e públicos não como contextos opostos, embora sejam noçôes diferentes, com muitas semelhanças. Para a autora, "a análise dos públicos centra-se numa tentativa de compreender o significado e as consequências das formas públicas, em oposição ao privado, em atividades ou espaços para essa atividade” (Livingstone, 2005, p. 35). De acordo com Livingstone, os média (tradicionais e novos média) fornecem uma janela para o mundo (Livingstone, 2005, p. 21) mediatizam, selecionam, atribuem prioridades, moldam, conforme as instituições, as tecnologias de informação e comunicação e as convençôes discursivas da indústria dos média. Sonia Livingstone refere-se a cidadania cívica (Livingstone, 2005, p. 34) para falar de um público retirado da privacidade, que é capaz de gerar capital social para conseguir um maior envolvimento com formas de identidade.

Ao nível organizacional, a gestão de crise e de riscos supõe uma atenção muito particular aos públicos, tanto do ponto de vista interno como do ponto de vista externo. É por isso que, no plano da comunicação, ao gestor convém definir grupos prioritários da ação informativa. Não obstante, com o desenvolvimento dos novos média e da internet e do movimento cada vez mais acentuado das pessoas, a gestão dos fluxos de informação deixa de poder ser encarada apenas local ou regionalmente. A globalização dos mercados e das sociedades em geral sugere a consideração de públicos num âmbito mais global, que incluem não só os públicos efetivos como os públicos potenciais.

\section{COVID-19, UMA CRISE GLOBAL}

"Vencer a guerra contra o novo coronavírus", foi assim que o Presidente de Portugal, Marcelo Rebelo de Sousa, se referiu à crise gerada em todo o mundo pela pandemia de coronavírus SARS-CoV-2, que provoca a doença de COVID-19. No final de janeiro de 2020, a Organização Mundial de Saúde (OMS) declarou o surto deste vírus como uma emergência de saúde pública de interesse internacional (OMS, 2020a). 
No dia 11 de março e após a avaliação permanente do surto e os alarmantes níveis de disseminação, gravidade e inação, a OMS declarou a COVID-19 como uma pandemia (OMS, 2020b). A globalização da doença transformou-se numa crise de magnitude mundial, que afetou todas as esferas da sociedade: saúde, economia, educação e quotidiano. E, consequentemente, desafiou as estratégias de comunicação desta crise, colocadas em prática por diferentes instituições com grande relevância social.

Durante uma fase de perturbação da ordem, principalmente nos primeiros momentos, é muito difícil manter a calma e dar as indicações adequadas, sobretudo quando há uma infinidade de variáveis de risco. A crise sanitária provocada pela pandemia adquiriu uma escala sem precedentes, com quadros de incerteza que dificultam qualquer exercício de previsibilidade. No entanto, é possível fazer uma preparação para enfrentar diferentes crises e, desta maneira, conseguir superá-las com mais possibilidades de sucesso.

Uma crise, sob o ponto de vista da comunicação, não é um evento, é um processo que exige preparação prévia de todos os que circundam um momento de atenção. Uma das figuras mais importantes em todos os processos é a do gestor de comunicação que deve transmitir informação para os públicos preferenciais, tendo como missão antecipar e acautelar os relatórios apresentados pelo porta-voz das diferentes instituiçóes.

Num período de turbulência, a busca por informação é uma constante para os diversos públicos e os média sociais desempenham um papel crucial nesse processo de comunicação. $\mathrm{O}$ espaço dos média sociais pode funcionar como um mecanismo de multiplicação, discussão e tomadas de posição de medidas governamentais e institucionais, pois, sendo uma situação excecional, os públicos podem entrar diretamente em diálogo com as instituiçốes. No caso da Universidade do Minho, a crise provocada pela COVID-19 implicou, precisamente, essa comunicação com diversas "camadas de informação", tendo em linha de conta a diversidade dos públicos preferenciais da instituição e dos novos públicos.

A crise na Universidade do Minho emergiu a 7 de março de 2020, quando a Ministra da Saúde de Portugal avançou com a notícia, em conferência de imprensa, do encerramento de algumas escolas e instituiçóes nacionais devido ao surto de coronavírus, 
entre as quais "o edifício do curso de História da Universidade do Minho" 2 . Parte das suas instalaçôes foram, assim, abruptamente encerradas e, com isso, emergiu um conjunto de preocupaçóes, sobre a dimensão do problema sanitário, sobre as condiçóes de prestação dos seus serviços, sobre a sua sustentabilidade económico-financeiras, entre outras. Nos dias seguintes, a equipa reitoral, com o apoio da Comissão de Elaboração e Gestão do Plano de Contingência Interno COVID-19 (nomeada por despacho reitoral de 3 de março), foi definindo um conjunto de medidas de resposta à crise. Gradualmente, a instituição foi encerrando edifícios e transferindo as atividades para o modelo de trabalho online e a 10 de março foram definitivamente suspensas todas as atividades letivas ${ }^{3}$. A situação de crise estava instalada, mas a magnitude das suas consequências era imprevisível.

Neste contexto, a comunicação com os públicos internos tornou-se urgente, assim como a relação com a comunidade externa, para partilhar informação, reduzir ansiedades e controlar o risco de agravamento da situação crítica. A Universidade comunicou predominantemente pelos meios online, com baixo grau de segmentação e seguindo uma estratégia assente em quarto eixos:

1) Comunicação contínua (incluindo despachos do Reitor que decretaram o encerramento dos complexos pedagógicos, restriçôes no funcionamento das residências universitárias, suspensão das atividades letivas, encerramento de bibliotecas e cantinas e regulamentação do teletrabalho, documentos esses que foram sendo partilhados nos meios online e anunciados em conferência de imprensa);

2) Gravidade da crise (através dos comunicados da "Comissão de Elaboração e Gestão do Plano de Contingência Interno COVID-19 da Universidade do Minho" e do aconselhamento das autoridades de saúde pública);

3) Uso dos meios de comunicação digitais (com o recurso ao website da instituição e às suas redes sociais, a criação da página COVID-19 no website UMinho, a publicação de vídeos de mensagens do Reitor e a partilha de todos os despachos e comunicados);

2 https://www.dn.pt/edicao-do-dia/08-mar-2020/18-pessoas-infectadas-em-portugal-11899337.html. 3 Despacho RT-25/2020. 
4) Unidade (pela elaboração de atividades no espaço digital por meio de conteúdos próprios, em diálogo com os diferentes públicos da instituição).

Esses quatro eixos orientadores, visavam enviar sinais de alerta à comunidade e mostravam a situação de vulnerabilidade de uma instituição que lutava contra uma crise inesperada (ainda que mais ou menos esperada). Com as notas informativas, os despachos reitorais e os comunicados oficiais sobre a nova pandemia, a Universidade procurava entrar em diálogo com os seus públicos para reduzir os riscos de agravamento da situação. Tudo isto num quadro de incerteza e falta de preparação.

Fundação pública de direito privado, fundada em 1973, a Universidade do Minho organiza-se atualmente em 11 escolas e acolhe cerca de 20 mil alunos, funcionando em dois campi (nas cidades de Braga e Guimarães). A UMinho dispóe de um Gabinete de Comunicação e Imagem que coopera com a Reitoria "na definição de políticas e estratégias de Comunicação e Imagem”“ Tendo sido um dos primeiros estabelecimentos académicos a suspender as atividades presenciais, a Universidade do Minho confrontou-se, desde o primeiro momento, com o desafio de gerir os efeitos da pandemia ao nível do ensino superior, um setor em que, ao contrário de outros, o processo de decisão exigiu conjugar as orientaçôes governamentais com a esfera de autonomia própria da instituição.

\section{O CASO DA UNIVERSIDADE DO MINHO}

O encerramento das instalaçóes da Universidade do Minho para prevenir um surto de COVID-19 (com início a 7 de março de 2020), constitui um dos acontecimentos mais marcantes da história da instituição. Contudo, este episódio foi vivido de forma idêntica por muitas organizações de ensino superior (IES) espalhadas pelo mundo, como retrata Knight (2020):

... estamos agora na quarta semana de um confinamento mundial... Com riscos especiais resultantes do facto de os estudantes trabalharem juntos em locais fechados, as instituições de ensino superior foram confrontadas com o problema

4 https://www.uminho.pt/PT/uminho/Unidades/Servicos, acedido a 26 de junho de 2020. 
de pensar o que fazer com muito pouca antecedência. Os campi residenciais tinham de decidir quando e como fechar dormitórios. Os professores precisavam de aprender como transferir as suas disciplinas para o online, muito rapidamente, a fim de preservarem uma certa aparência de continuidade. Algumas faculdades e universidades já tinham planos para lidar com uma crise, embora a magnitude desta não tenha precedentes... com a pandemia de COVID-19, os desafios foram gigantescos. (Knight, 2020, p. 131)

Procurando analisar o comportamento comunicativo desta universidade no momento em que a crise eclodiu, foi levado a cabo um estudo de caso sobre a relevância do diálogo na comunicação com os públicos no processo de gestão da crise COVID-19. A metodologia do estudo de caso (Yin, 2014) tem dominado a pesquisa em Comunicação de Crise (Coombs \& Holladay, 2010) e é amplamente usada nas investigações sobre IES (Ruão, 2008). Os estudos de Comunicação de Crise parecem ter começado com a análise de casos concretos no mundo profissional, que depois foram explorados academicamente, na expetativa de desenvolver teoria (por exemplo, Coombs, 2010; Dawar e Pillutla 2000; Seeger, Sellnow \& Ulmer 1998).

Ainda que os estudos de Comunicação de Crise se tenham concentrado na análise do setor com fins lucrativos, acreditamos na particular relevância de analisar a atuação das instituiçóes públicas em momentos de crise. Na verdade, perante uma ameaça, os cidadãos tendem a procurar no setor público a responsabilidade da resposta inicial à crise, pelo que a vitalidade das redes de comunicação do setor público é essencial para o cumprimento da sua missão social (Gainey, 2010). Daí julgarmos oportuno o estudo da campanha de gestão do risco levada a cabo por uma universidade pública.

\section{Origem da campanba "UMinho Online"}

Face à suspensão das atividades letivas presenciais das IES em Portugal, a partir de março de 2020 e no contexto da pandemia de COVID-19, o Ministério da Ciência, Tecnologia e Ensino Superior sugeriu que as universidades e institutos politécnicos portugueses desenvolvessem "esforços para estimular processos de ensino-aprendizagem 
à distância" e a "interação por via digital entre estudantes e docentes"s. Desde os primeiros dias do encerramento das suas instalaçóes e na mesma linha de entendimento, a Universidade do Minho "procurou encontrar soluções e apostou em maximizar o sucesso da transição de ensino presencial para ensino mediado por tecnologia" ${ }^{6}$. Neste contexto, a reitoria da Universidade contactou o Instituto de Ciências Sociais (escola onde está sediada a área de especialização e conhecimento em Ciências da Comunicação), solicitando a preparação de uma campanha para os públicos internos, destinada a promover a adesão à modalidade de ensino à distância e ao teletrabalho.

Tratava-se de uma campanha de Comunicação de Risco, a ser levada a cabo no contexto da situação crítica da instituição. Como vimos na revisão da literatura, a Comunicação de Risco pode ser usada como resposta às crises, enquanto mecanismo de contenção que procura sensibilizar os públicos sobre a necessidade de adotarem comportamentos seguros (Coombs, 2010; Sturges 1994). Seguindo estes pressupostos, a Universidade resolveu avançar com uma campanha, com os seguintes propósitos: (1) informar os seus públicos internos sobre as regras de comportamento em situação de pandemia e (2ํㅡ) motivá-los para a necessária mudança comportamental (para o trabalho online), de modo a proteger a comunidade interna e a evitar o agravamento da situação de crise.

Para responder às necessidades da reitoria da Universidade, a equipa de Comunicação (que integrou os autores deste capítulo) começou por realizar um estudo de benchmarking. Trata-se de uma análise destinada à identificação e compreensão de boas práticas levadas a cabo por organizaçóes em todo o mundo, com o objetivo de repensar o modo de atuar das empresas/instituições com base em modelos já testados (Anand \& Kodali, 2008). O estudo incluiu a análise das campanhas de comunicação de outras universidades no âmbito do surto de COVID-19, avaliando os seus padróes de atuação. Procedeu-se à adaptação do famoso modelo de benchmarking da Xerox (Anand $\&$ Kodali, 2008) e foram realizadas as etapas de pesquisa seguintes: (1o) identificação dos casos a estudar, tendo em conta o grau de proximidade do ambiente de atuação da UMinho e procurando países com uma diversidade de situações pandémicas (em

5 Nota de Esclarecimento do MCTES, de 13 de março.

6 Nota do Gabinete de Comunicação, Informação e Imagem da Universidade do Minho, de 18 de março. 
março de 2020); (2) definição dos métodos de recolha de dados, que incluíram a análise dos websites e redes sociais das universidades (pela facilidade e rapidez de acesso); (3) categorização e interpretação dos dados recolhidos, cujos resultados apresentamos de seguida e (4) incorporação dos resultados numa proposta estratégica.

Esta pesquisa foi organizada por países. Começámos pelo caso de Itália, país onde a pandemia atingia já níveis de enorme gravidade e os resultados da observação permitiam concluir que as universidades enviavam sobretudo mensagens informativas sobre o modo como se ia instalando o ensino à distância e como se procedia à reestruturação de algumas atividades em função da situação de crise (como é o caso das cerimónias de graduação). De seguida, procedeu-se ao estudo da comunicação das universidades em França, local onde a pandemia começava a dar sinais de alarme. Aqui as instituições limitavam-se a informar os públicos sobre o encerramento das instalações e sobre os modelos de funcionamento do ensino à distância. Em Espanha, as universidades estavam a fornecer guias para o uso das novas plataformas de ensino à distância, sendo que algumas apostavam em vídeos para envolver os seus estudantes, informar sobre a COVID-19 e as implicações para a universidade. No Reino Unido, onde o surto de COVID-19 estava no seu início, as universidades mantinham o seu modelo de comunicação clássico, informando sobre a situação pandémica e mostrando que investigações estavam a ser desenvolvidas na instituição para ajudar as comunidades, com particular destaque para a descoberta da vacina para o novo coronavírus. Na Holanda, as universidades mostravam uma aparente normalidade, colocando a informação sobre a pandemia a par com a divulgação de atividades programadas, num modelo de comunicação de "baixo perfil" (Caponigro, 2000). Na Bélgica, as instituições tiravam partido do envolvimento dos seus investigadores em pesquisas relacionadas com a pandemia, cobrindo áreas como a medicina, a biologia ou as ciências sociais. Nos EUA, num período em que o contágio era ainda baixo, as universidades mostravam estar conscientes da situação de pandemia, mas a sua informação era ainda incipiente. E em Portugal, as IES combinavam as campanhas a favor do isolamento social com a prestação de informação sobre o ensino à distância.

De modo sumário, podemos dizer que as mensagens eram sobretudo informativas e de baixo envolvimento. Embora se registassem também alguns bons exemplos de 
conteúdos apelativos, envolventes e/ou emocionais, como nas redes da Universidade de Bolonha ${ }^{7}$, ou da Universidade Autónoma de Madrid $^{8}$ e no website do MIT'. Os canais preferenciais eram o email, o website e as redes sociais. Os média eram entendidos como canais coadjuvantes (para a comunicação com públicos externos). Os websites institucionais apresentavam como assunto predominante a COVID-19 e continham ligações para informação epidemiológica, normas e regulamentos, plataformas de ensino à distância, depoimentos de especialistas (internos), projetos de investigação relacionados com a pandemia, práticas de solidariedade, entre outros assuntos regulares na vida de uma academia. As redes sociais constituíam extensóes do website, replicando informaçôes sobre regras, práticas e pesquisa relacionadas com a COVID-19, bem como informações gerais sobre atividades letivas e de investigação. Incluíam ainda campanhas de apelo ao confinamento e distância social, e ao envolvimento nas novas práticas de ensino e pesquisa. Como meios preferenciais, destacaram-se as declaraçóes escritas (textos informativos e cartas abertas), os despachos e normas, os vídeos (com declarações, entrevistas, depoimentos pessoais e mensagens motivacionais), os cartazes (informativos e de envolvimento) e as fotografias (dos campi, das pessoas ou dos novos ambientes de trabalho).

A principal tendência estratégica de comunicação consistia em associar o apelo ao isolamento social - com hashtags como "\#stayhome" - à necessidade do ensino à distância - tendo como eixo de comunicação a ideia de que o teletrabalho era uma necessidade em tempos de emergência e não uma opção. Esta mensagem era partilhada em peças de comunicação várias, como textos, cartazes, flyers ou guias/tutoriais, através dos canais online.

\section{Estratégia desenhada para a campanha}

Depois de elaborado e partilhado o relatório de benchmarking, foi definida uma estratégia de comunicação para a Universidade do Minho, que teve como alvo primário

7 https://www.inst agram.com/unibo/ (consulta março/abril 2020).

8 https://www.instagram.com/p/B91LbBxADAi/ (consulta março/abril 2020).

9 http://www.mit.edu/ (consulta março/abril 2020). 
o público interno - estudantes, docentes e funcionários - e, marginalmente, a comunidade local e nacional. Como objetivos de comunicação foi identificado um conjunto de intençôes: (1o) melhorar a compreensão das circunstâncias extraordinárias em que a comunidade académica se encontrava; (2o) motivar para a adoção de processos de ensino-aprendizagem tecnologicamente mediados; (3) apelar à participação na construção conjunta das melhores soluçốes de ensino à distância e (4ํo) vencer resistências relativamente à adoção do teletrabalho.

Tendo em vista um aprofundamento da compreensão das ideias, atitudes e comportamento dos nossos públicos-alvo face à situação extraordinária que viviam, procedemos a uma análise da interação nas redes sociais da UMinho (Facebook e Instagram). Pretendíamos encontrar barreiras percetuais a superar e localizar oportunidades de comunicação. Nesse quadro, chegamos a um conjunto de insights, ou representaçóes mentais sobre a situação por parte dos públicos, que sintetizamos no Quadro 1.

Quadro 1. Estudo das perceções e atitudes dos públicos internos.

Os Docentes consideram que...

«O ensino à distância dá muito trabalho»

«O ensino à distância implica conhecimentos técnicos que não tenho e que demoram muito tempo e esforço a adquirir»

«O ensino à distância não funciona»

«Vivemos uma situação temporária de emergência que não deveria exigir tanto esforço da nossa parte»

«Quero ajudar. Quero ser solidário. Quero proteger e ser protegido»

$\cdots$

Os Estudantes consideram que...

«O ensino à distância é chato»

«O ensino à distância exige aprendizagens técnicas difíceis»

«O ensino à distância centra-se no trabalho individual»

«Vivemos uma situação temporária de emergência que não deveria exigir tanto esforço da nossa parte»

«Eu não entrei para esta Universidade para ter aulas à distância»

«Quero ajudar. Quero ser solidário. Quero proteger e ser protegido» 
Os Funcionários consideram que...

«O teletrabalho vai interferir com a minha vida familiar»

«O teletrabalho vai transferir custos de funcionamento para o meu orçamento familiar»

«Há tarefas que não podem ser realizadas em teletrabalho»

«Vivemos uma situação temporária de emergência que não deveria exigir tanto esforço da nossa parte»

«Quero ajudar. Quero ser solidário. Quero proteger e ser protegido»

$\cdots$

Com base no estudo de benchmarking, no modelo de comunicação já instalado na UMinho (tradicionalmente corporate) e na avaliação dos nossos públicos, definimos que a campanha deveria ter um tom institucional, integrar os diferentes públicos e passar a seguinte mensagem-chave:

Eixo de Comunicação - «Circunstâncias excecionais exigem medidas excecionais, por parte da Universidade e da Sociedade como um todo. Neste contexto, o teletrabalho e o ensino à distância não são uma opção da instituição, mas uma necessidade em tempos de emergência. A compreensão, colaboração, participação e solidariedade de todos é fundamental para fazer face às novas necessidades. Todos somos parte da solução».

Da identificação deste eixo, resultou um conceito de comunicação (ou uma ideia criativa para a campanha):

«Universidade unida. Universidade solidária.»

Este conceito foi ainda desdobrado em diferentes assinaturas nas seis fases da campanha (Quatro 2), que respondiam o modelo AIDA. Este modelo define as etapas cognitivas que podem ser motivadas por uma mensagem persuasiva quando atua na mente dos públicos e que foram identificadas como: Atenção, Interesse, Desejo e Ação (Joannis, 1998). 
Quadro 2. Desdobramentos da campanha.

\begin{tabular}{|c|c|c|}
\hline Etapas/Efeito & Públicos & Assinatura \\
\hline 1므 FASE/Atenção & $\begin{array}{l}\text { Comunidade } \\
\text { universitária }\end{array}$ & Universidade unida. Universidade solidária. \\
\hline 2a FASE/Interesse & $\begin{array}{l}\text { Comunidade } \\
\text { universitária }\end{array}$ & Universidade à distância. Universidade solidária. \\
\hline 3르 FASE/Desejo & $\begin{array}{l}\text { Estudantes } \\
\text { Docentes }\end{array}$ & Ensino à distância. Ensino solidário. \\
\hline 4⿳亠丷a FASE/Ação & Funcionários & Universidade em casa. Universidade solidária. \\
\hline 5ㅁ FASE/Reforço & Escolas & Escolas unidas. Universidade solidária. \\
\hline 6a FASE/Reforço & Serviços & Serviços presentes. Universidade solidária. \\
\hline
\end{tabular}

Estas frases assinavam mensagens institucionais diárias - de tom próximo, emotivo e caloroso -, escritas no tipo de letra definido no Manual de Identidade da Universidade - NewsGot $T$ - e que estavam inseridas em cartazes e banners com imagens representativas da comunidade interna e de ambientes de trabalho e ensino à distância, onde predominavam as cores do logótipo da UMinho e das suas escolas. As peças de comunicação foram colocadas no website e nas redes da Universidade (Facebook e Instagram) e eram também partilhadas nas redes sociais das unidades orgânicas. A campanha teve ainda uma versão em inglês, para atingir os estudantes, docentes e investigadores internacionais a trabalhar nos campi. Nas redes, os cartazes assumiram a forma de gifs para que as duas versôes linguísticas - português e inglês - fossem mais visíveis.

A campanha decorreu entre 30 de março e 13 de maio de 2020, incluiu duas publicações diárias (uma de manhã e outra de tarde), numa estratégia de partilha cruzada entre os canais da Universidade e os das suas Escolas (Figura 1). 

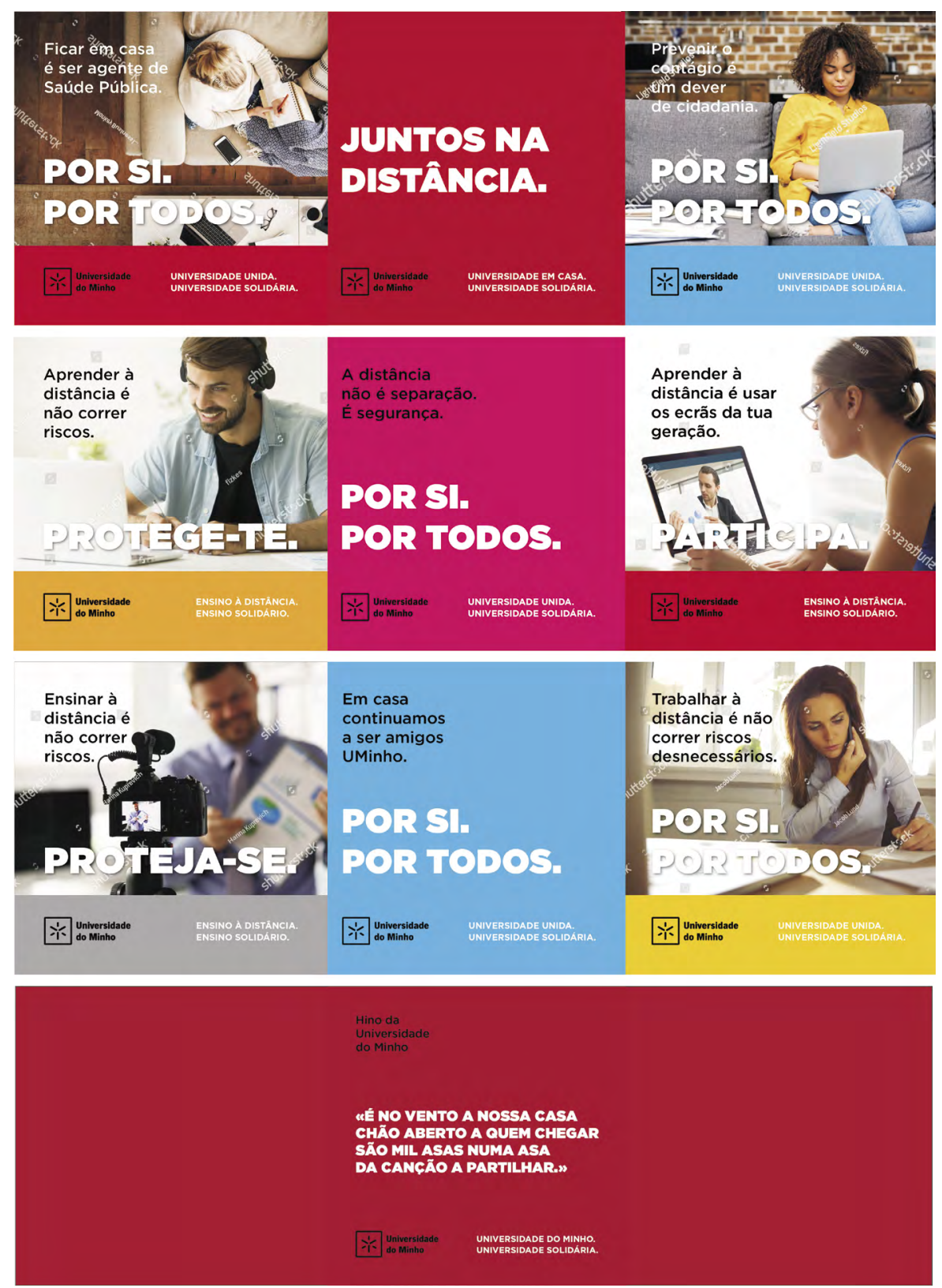

Figura 1. Exemplos de imagens das fases 1 a 4 .

As fases iniciais da campanha corresponderam a momentos de desenvolvimento de visibilidade do tema (ATENÇÃO), com declaraçôes como "O isolamento social é sinal de respeito e responsabilidade" ou "Prevenir o contágio é um dever de cidadania"; de promoção de familiaridade (INTERESSE) com a ideia de 'distância na proximidade', com afirmações como "Trabalhar à distância é não correr riscos desnecessários" ou "O longe pode fazer-se perto de múltiplas formas"; de redução de preconceitos e estímulo a novas práticas (DESEJO), com proposições como "Ensinar é um exercício 
de partilha. Mesmo à distância" ou "Ensinar à distância é partilhar ecrãs, é partilhar a vida" e de promover o envolvimento claro dos públicos, com testemunhos como "A UMinho em tua casa. Ensino seguro" ou um excerto do hino da instituição que apela à ideia de 'casa comum'.

As fases 5 e 6 promoveram a memorização da mensagem e procuraram reforçar atitudes e comportamentos responsáveis, apelando à união entre as escolas da Universidade e ao reconhecimento do papel dos serviços. Se os cartazes iniciais usaram imagens compradas, pela necessidade de reação rápida, as imagens das fases 5 e 6 correspondem a fotografias reais dos locais de trabalho dos públicos internos (incluindo as suas habitações próprias), num exercício de personalização e aproximação.

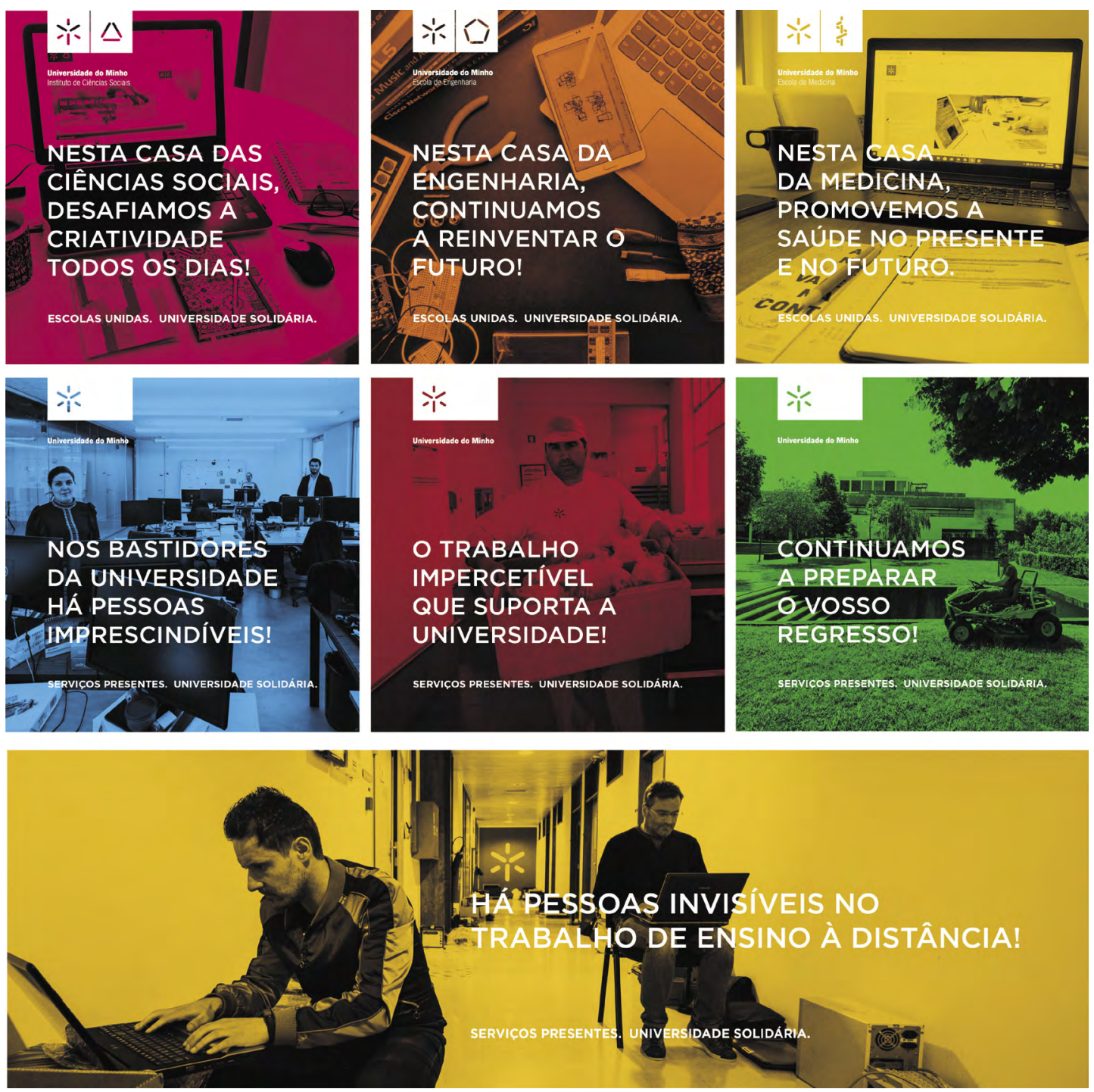

Figura 2. Exemplos de imagens das fases 5 e 6. 
Quanto aos efeitos da campanha, estes só poderão ser aferidos no longo prazo, já que se pretendeu atuar sobre perceçóes, atitudes e comportamentos, ou seja, fatores não detetáveis na contagem de likes, partilhas e visualizaçôes. Ainda assim, a campanha procurou cumprir as regras da comunicação de crise e da comunicação de pandemias, atendendo à preparação de mensagens informativas e empáticas, enviadas através de canais próximos dos públicos prioritários (Knight, 2020).

\section{Discussão}

A gestão de crises em IES portuguesas não constituiu uma área estudada na academia ou debatida por profissionais, mas nos EUA a temática tem sido amplamente discutida pelas próprias universidades e escolas públicas. Tiroteios, desastres naturais ou intoxicaçôes alimentares serviram como alerta para a necessária valorização do planeamento da gestão de crises. $\mathrm{O}$ momento de mudança parece ter sido o trágico tiroteio na Columbine High School, a 20 de abril de 1999 (com a morte de 12 estudantes e um professor), que trouxe a temática da gestão de crises definitivamente para o centro da discussão entre educadores no setor público (Kleinz 1999). Este acontecimento, como outros, criou um sentido de urgência no envolvimento verdadeiramente significativo dos públicos, muitas vezes desligados da sua comunidade escolar. Em contexto de emergência, as organizações escolares americanas perceberam a importância da criação estratégica de canais de comunicação como mecanismos de sobrevivência (Gainey, 2010).

A gestão das crises no setor da educação parece implicar o estabelecimento de melhor comunicação e relacionamentos nas escolas e entre as escolas e as comunidades. "Envolver o público" significa buscar a participação plena de um grupo mais amplo de constituintes (Wadsworth, 1997). Neste quadro, é essencial o aumento da colaboração, a aposta na comunicação, o fortalecimento do relacionamento com a comunidade e lideranças visionárias para manter os projetos escolares dinâmicos e seguros (Gainey, 2010).

A comunicação das crises atuais envolve novas capacidades e perigos desconhecidos, pois implica gerir a relação com os média tradicionais, mas gerir igualmente a interação que acontece na Internet e que exige novas parcerias com os stakebolders. Uma gestão de crises eficaz implica que as organizaçôes identifiquem os seus principais públicos 
no caso de uma emergência e ainda que adotem canais de comunicação bidirecionais. Um estudo de Paul (2001) indicou que as pessoas que usam a Internet como fonte de informação durante uma crise preferem fontes interativas a fontes estáticas. No entanto, outras pesquisas recentes descobriram que as organizaçóes não estão a fazer um bom trabalho no aproveitamento das oportunidades dialógicas oferecidas pelos novos média (Kent \& Taylor 1998; Kent, Taylor \& White 2003; Jo \& Kim 2003; Stephens \& Malone, 2010).

A análise do caso da Universidade do Minho deve ser inserida neste contexto de problemas e práticas globais, que demonstram a importância do diálogo com os públicos nos processos de gestão de crises. Trata-se de um diálogo que hoje parece passar necessariamente pelos média sociais. O crescimento das redes sociais como o Facebook, o Twitter e o Instagram, quer em termos de número de utilizadores quer de popularidade (Andrade, 2016), bem como a existência de alternativas - como o Consumer-Generated Media (CGM) e o User-Generated Content (UGC) (Kaplan \& Hanenlein, 2010) e os novos média (Flew, 2008; Lister et al. 2009; Manovich, 2002;) - contribuem para profundas transformações no consumo dos cidadãos. Além da procura de informação em tempos de crise, as pessoas (públicos) (re)criam conteúdos que disponibilizam na Internet, participando ativamente na definição da situação.

A campanha "UMinho Online" pretendeu gerir a reação dos stakebolders (Coombs, 2009) à situação de crise, promovendo uma certa interpretação do assunto, confiante e motivada, ao mesmo tempo que fazia a gestão do risco. O risco correspondia ao cenário da não adoção de comportamentos adequados pelos membros da academia ou da perda de reputação por parte da instituição, o que poderia ter aprofundado a situação já crítica. Por isso, as mensagens apelavam à contenção, à motivação para a proteção individual e organizacional e à adoção de novas práticas, enquanto procuravam reduzir resistências e ultrapassar preconceitos. Tratou-se, portanto, de um caso de uso da Comunicação de Risco numa situação de crise já instalada, mas cujo agravamento se pretendia evitar. Ao mesmo tempo que não deixou de integrar algumas funções de Comunicação de Crise, com a introdução de declarações informativas, de apelos à solidariedade institucional ou à confiança na gestão de topo e nas autoridades. 
Para conseguir estes efeitos, foi desenvolvida uma estratégia de uso articulado dos canais digitais da Universidade do Minho, incluindo as páginas de Facebook, Instagram e Twitter das diversas escolas. Foi no formato digital, que se observou a convergência e a partilha que distingue os média sociais dos meios de comunicação tradicionais (Flew, 2008; Livingstone, 2002; Manovich, 2002). Contudo, exigia-se uma maior articulação na gestão dos contactos e conteúdos com ambos os meios, tendo a Universidade usado frequentemente as mesmas mensagens para os média e para os públicos digitais e negligenciado uma gestão estratégica dos timings de envio das mensagens para estes públicos. Isso conduziu a perdas de comunicação significativas (pela dispersão de atenção e perda de confiança no emissor), que poderiam ter sido evitadas na presença de uma comunicação digital articulada com o processo de assessoria de imprensa, também este cada vez mais atravessado pelo uso dos canais digitais. Contudo, a segmentação dos públicos continua a ser necessária nos meios de comunicação digitais e essa falha pode ter efeitos profundos em momentos de crise.

A campanha "UMinho Online" correspondeu ainda àquilo que Sturges (1994) designa de comunicação de ajustamento. Incluiu mensagens de aconselhamento ou expressões de simpatia, que pretendiam desenvolver a sensibilidade dos stakebolders ao risco e levá-los ao ajustamento comportamental. A compreensão dos assuntos parece melhorar a reação dos stakeholders a situações de risco ou crise, mas não chega. É importante gerar a motivação emocional que está na base de todas as relaçóes humanas e esse parece ser o ponto-chave de um diálogo que promove alteraçóes no conhecimento, comportamento e práticas. Além de ser esse envolvimento que gera a transferência do estado de stakeholders para "nossos públicos e novos públicos”, a que os canais digitais tentam dar resposta, seja no (re)conhecimento das interaçôes (likes e partilhas), seja na necessidade de responder de forma mais ágil, como nos comentários das publicações que foram aqui apresentadas. Nesse sentido, entendemos a motivação emocional na Comunicação de Crise como uma forma de cidadania cívica, fundamental na vida das instituições públicas. 


\section{CONSIDERAÇÕES FINAIS}

Embora se defina como uma crise sanitária, de impacto na saúde pública, a pandemia COVID-19 ampliou também a crise da própria instituição universitária. A resposta que as universidades encontraram para continuar as suas atividades agudizou o debate público sobre a natureza e a missão da academia. No espaço público, a ação das universidades foi analisada mais pelo prisma das soluções implementadas para superar os efeitos da suspensão da atividade presencial do que pelas estratégias de comunicação das ações desenvolvidas. A adoção de um modelo de ensino tecnologicamente mediado, com sinais de se prolongar para além do período oficial de confinamento, agravou a perceção de que as universidades cedem a uma espécie de fascínio pela virtualização. Num texto publicado no jornal Público, a 4 de junho, Manuel Loff, por exemplo, reconhecia que as universidades parecem iludidas com uma transição digital que, se não for parada, desvirtuará definitivamente a função social e cultural da universidade pública, acentuará um velho processo de recentralização, hierarquização e empresarialização e dissolverá comunidades abertas de professores, estudantes e funcionários onde historicamente houve sempre vocação democrática (Loff, 2020).

Considerando que o estado de emergência "está a abrir brechas e perigosas fissuras nos pilares institucionais” da universidade, António Bento, professor da Universidade da Beira Interior, alertava no mesmo jornal para o perigo de um certo confinamento tecnológico da universidade:

A completa desterritorialização da universidade implicada no fetichismo tecnológico do "ensino à distância”, para além de esvaziar as "casas do saber" a que chamamos universidades, e de isolar uns dos outros os seus potenciais frequentadores, ignora uma lição didática elementar, a saber, que a transmissão do conhecimento científico exige corpos carnalmente expostos uns aos outros. (Bento, 2020)

A estratégia de comunicação da Universidade do Minho no contexto da crise pandémica foi, em grande medida, orientada para a promoção do ensino à distância e do teletrabalho como medidas de exceção para um tempo igualmente excecional. Determinada pelo objetivo específico de mobilizar a comunidade académica para uma mudança temporária de paradigma, a campanha de comunicação de que demos conta 
neste capítulo visou sensibilizar os diferentes públicos - os estudantes, os professores e os funcionários - para a necessidade de um comprometimento universal. Com um enfoque muito centrado no imediato, procurou ser essencialmente um exercício de exortação para os imperativos do momento. Apresentada como a via única para corresponder ao dever de dar continuidade à sua missão em condições de segurança, a implementação de um plano de "universidade virtual" abriu, no entanto, o horizonte a uma crise que, não sendo nova, se prolongará para além da crise pandémica propriamente dita, a crise de identidade da academia, que deverá manter a Universidade do Minho e as universidades em geral, em alerta e particularmente ativas nos bastidores da comunicação de risco.

\section{REFERÊNCIAS}

Anand, G., \& Kodali, R. (2008). Benchmarking the benchmarking models. Benchmarking: An international journal-15(3), 257-291.

Andrade, J. (2016). Relaçóes Públicas e mídia sociais: os desafios da gestão com os públicos. In: Túñez López, M; Costa-Sánchez, C. (Eds.), Interação organizacional na sociedade em rede. Os novos caminhos da comunicação na gestão das relações com os públicos (pp. 121-136). La Laguna (Tenerife): Latina.

Beck, U. (2000): Risk society: towards a new modernity. Londres: Sage Publications.

Benoit, W. L. (1997). Image repair discourse and crisis communication. Public relations review, 23(2), 177186. http://dx.doi.org/10.1016/S0363-8111(97)90023-0.

Bento, A. (2020, 13 de junho). Pandemia e "ensino à distância": Hey, teachers, don't leave your students alone. Público. Retirado de https://www.publico.pt/2020/06/13/sociedade/opiniao/pandemia-ensinodistancia-hey-teachers-dont-leave-your-students-alone-1920454.

Benson, J. A. (1988). Crisis revisited: an analysis of strategies used by Tylenol in the second tampering episode. Communication Studies, 39(1), 49-66. https://doi.org/10.1080/10510978809363234.

Botan, C., Soto, F. (1998). A semiotic approach to the international functioning of publics: implications for Strategic Communication and Public Relations. Public Relations Review, 24(1), 21-44. https://doi. org/10.1016/S0363-8111(98)80018-0.

Burgoon, M., Pfau, M., \& Birk, T. S. (1995). An inoculation theory explanation for the effects of corporate issue/advocacy advertising campaigns. Communication Research, 22(4), 485-505. https://doi. org/10.1177/009365095022004006.

Caponigro, J. R. (2000). The crisis counselor: a step-by-step guide to managing a business crisis. London: McGraw-Hill Companies. 
Coombs, W. T. (1999). Information and compassion in crisis responses: A test of their effects. Journal of Public Relations Research, 11(2), 125-142.https://doi.org/10.1207/s1532754xjprr1102_02.

Coombs, W. T. (2007). Protecting organization reputations during a crisis: The development and application of situational crisis communication theory. Corporate Reputation Review, 10(3), 163-176. https://doi.org/10.1057/palgrave.crr.1550049.

Coombs, W. T. (2009). Conceptualizing crisis communication. In R. L. Heath \& R. L. O'Hair(Eds). Handbook of risk and crisis communication (pp. 99-118), NY: Routledge.

Coombs, W. T. (2014). Ongoing crisis communication: Planning, managing, and responding. USA: Sage Publications.

Coombs, W. T., \& Holladay, S. J. (Eds.). (2010). The handbook of crisis communication, Singapure: John Wiley \& Sons.

Coombs, W.T. (2010). Paramters for Crisis Communication. In Coombs \& Holladay (Eds), The handbook of crisis communication (pp. 17-53). Singapure: John Wiley \& Sons.

Dawar, N., \& Pillutla, M. M. (2000). Impact of product-harm crises on brand equity: The moderating role of consumer expectations. Journal of marketing research, 37(2), 215-226. https://doi.org/10.1509/ imkr.37.2.215.18729.

Dyer, K. (2010). Do you need a thorough guide to planning pandemic communication? Strategic Communication Management Summit, London.

Eiró-Gomes, M. Duarte, J. (2005). Que públicos para as Relaçôes Públicas. Actas do III SOPCOM, VI LUSOCOM e II IBÉRICO - Volume II, 453-461.

Fink, S. (1986). Crisis management: Planning for the inevitable. USA: Amacom.

Flew, T. (2008). New media: an introduction. Oxford: Oxford University Press

Gainey, B. S. (2010). Educational crisis management practices tentatively embrace the new media. In W. T. Coombs \& S. J. Holladay (Eds.), The handbook of crisis communication (pp. 301-318). Singapure: John Wiley $\&$ Sons.

Grunig, J., Repper, F. (1992) Strategic Management, Publics and Issues. In J. Grunig (Ed.), Excellence in Public Relations and Communications Management. New Jersey: Lawrence Erlbaum Associates.

Heath, R.L. (2010). Introduction. In W. T. Coombs \& S. J. Holladay (Eds). The handbook of crisis communication (pp. 1-14), Singapure: John Wiley \& Sons.

Holton, R. J. (1987). The idea of crisis in modern society. The British Journal of Sociology, 38(4), 502-520. https://doi.org/10.2307/590914.

Hurst, D. K. (1995). Crisis and renewal: Meeting the challenge of organizational change. Boston: Harvard Business School Press. 
Jo, S., \& Kim, Y. (2003). The effect of web characteristics on relationship building. Journal of Public Relations Research, 15(3), 199-223. https://doi.org/10.1207/S1532754XJPRR1503_1.

Joannis, H. (1998). O processo de criação publicitária. Lisboa: Edições Cetop.

Kaplan, A., Haenlein, M. (2010). "Users of the World, Unite" The Challenges and Opportunities of Social Media, Business Horizons, 53(1), 59-68.

Kent, M. L., \& Taylor, M. (1998). Building dialogic relationships through the World Wide Web. Public Relations Review, 24(3), 321-334. https://doi.org/10.1016/S0363-8111(99)80143-X.

Kent, M. L., Taylor, M., \& White, W. J. (2003). The relationship between Web site design and organizational responsiveness to stakeholders. Public Relations Review, 29(1), 63-77. https://doi.org/10.1016/S0363$\underline{8111(02) 00194-7 .}$

Knight, M. (2020). Pandemic Communication: A New Challenge for Higher Education. Business and Professional Communication Quarterly, 83(2), pp. 131-132. https://doi.org/10.1177/2329490620925418.

Koselleck, R. \& Richter, M. W. (2006). Crisis. Journal of the History of Ideas, 67(2), 357-400. Retirado de https://www.jstor.org/stable/30141882.

Lister, M., Dovey, J., Giddings, S., Grant, I. e Kelly, K. (2009). New Media: A critical introduction. New York: Routledge.

Littlefield, R., Rowan, K., Veil, S. R., Kisselburgh, L., Beauchamp, K., Vidoloff, K., ... \& Wang, Q. (2012). We tell people. It's up to them to be prepared. Public Relations Practices of Local Emergency Managers. In W. T. Coombs \& S. J. Holladay (Eds.), The handbook of crisis communication (pp. 245-260). Singapure: John Wiley \& Sons.

Livingstone, S. (2002). Handbook of New Media. Thousand Oaks, London and New Delhi: Sage.

Livingstone, S. (2005). On the relation between audiences and publics. Audiences and Publics. Bristol e Portland: OR: Intellect Books

Loff, M. (2020, 4 de junho). A universidade e a ilusão digital. Público, 9.

Manovich, L. (2002). The language of new media. Cambridge: The MIT Press.

Martins, M. L. (2017). Crise no castelo da cultura - das estrelas para os ecrãs. Ribeirão: Húmus.

Meyers, G. C., \& Holusha, J. (2018). Managing crisis: A positive approach, London: Routledge.

Millar, D. P., \& Heath, R. L. (Eds). (2003). Responding to crisis: A rhetorical approach to crisis communication. New Jersey: Routledge.

Palenchar, M. J. (2005). Risk communication. In Encyclopedia of Public Relations (pp. 752-755). Thousand Oaks, CA: Sage. 
Paul, M. J. (2001). Interactive disaster communication on the Internet: a content analysis of sixty-four disaster relief home pages. Journalism \& Mass Communication Quarterly, 78(4), 739-753. https://doi. org/10.1177/107769900107800408.

Regester, M. (1989). Crisis management: what to do when the unthinkable happens. London: ButterworthHeinemann.

Reynolds, B., \& Seeger, M. (2005). Crisis and emergency risk communication as an integrative model.Journal of health communication, 10(1), 43-55. https://doi.org/10.1080/10810730590904571.

Salgado, P., Ruão, T., \& Machado, S. (2015). Managing reputational risk at Bosch car multimedia-Portugal: Creating safety nets through corporate communication programs. Observatorio $\left(O B S^{*}\right), 9(3), 33-46$. https:// doi.org/10.15847/obsOBS932015821.

Ruão, T. (2008). A Comunicação Organizacional e os fenómenos de identidade: a aventura comunicativa da formação da Universidade do Minho, 1974-2006. Tese de Doutoramento. Universidade do Minho, Braga, Portugal.

Seeger, M. W. (2006). Best practices in crisis communication: An expert panel process. Journal of Applied Communication Research, 34(3), 232-244. https://doi.org/10.1080/00909880600769944.

Seeger, M. W., Sellnow, T. L., \& Ulmer, R. R. (1998). Communication, organization, and crisis. Annals of the International Communication Association, 21(1), 231-276. https://doi.org/10.1080/23808985.1998.11678952.

Serra, P. (2006). Os riscos da comunicação na comunicação dos riscos. Biblioteca Online de Ciências da Comunicação. Retirado de http://www.bocc.ubi.pt/pag/serra-paulo-riscos-da-comunicacao.pdf.

Smith, D. (1990). Beyond contingency planning: Towards a model of crisis management. Industrial Crisis Quarterly, 4(4), 263-275. Retirado de www.jstor.org/stable/26162888.

Stephens, K. K., \& Malone, P. (2010). New media for crisis communication: Opportunities for technical translation, dialogue, and stakeholder responses. In W. T. Coombs \& S. J. Holladay (Eds). The handbook of crisis communication (pp. 381-395). Singapure: John Wiley \& Sons.

Sturges, D. L. (1994). Communicating through crisis: A strategy for organizational survival. Management Communication Quarterly, 7(3), 297-316. https://doi.org/10.1177/0893318994007003004.

Thomä, D., Festl, M. G. \& Grosser, F. (2015). Einstimmung: vier Etappen der Geschichte von Kritik und Krise, Studia Philosophica, Vol. 74/2015: Über Kritik und Krise.

Ulmer, R. R., Seeger, M. W., \& Sellnow, T. L. (2007). Post-crisis communication and renewal: Expanding the parameters of post-crisis discourse. Public Relations Review, 33(2), 130-134. https://doi.org/10.1016/j. pubrev.2006.11.015.

Vaughan, E., \& Tinker, T. (2009). Effective health risk communication about pandemic influenza for vulnerable populations. American Journal of Public Health, 99(2), 324-332. https://doi.org/10.2105/AJPH.2009.162537.

Virilio, P. (2000). A velocidade de libertação. Lisboa: Relógio d’Água. 
WHO (2020a). 2019-nCoV outbreak is an emergency of internacional concern. World Health Organization. http://www.euro.who.int/en/health-topics/health-emergencies/coronavirus-COVID-19/ news/news/2020/01/2019-ncov- outbreak-is-an-emergency-of-internacional-concern.

WHO (2020b). WHO Director-General's opening remarks at the media briefing on COVID-19 - 11 March 202011 de março de 2020. World Health Organiza on. https://www.who.int/es/dg/speeches/detail/whodirector-general-s-opening-remarks-at-the-media-brie ng-on-COVID-19-11-march-2020.

Williams, D. E., \& Olaniran, B. A. (1998). Expanding the crisis planning function: Introducing elements of risk communication to crisis communication practice. Public Relations Review, 24(3), 387-400. https://doi. org/10.1016/S0363-8111(99)80147-7.

Witt, J. L., \& Morgan, J. (2003). Stronger in the broken places: Nine lessons for turning crisis into triumph. USA: Macmillan.

Yin, R. K. (2014). Case study research: design and methods. Thousand Oaks: Sage Publications. 